\title{
0840 FACTORS PROTECTING SKIN FROM INJURY: RELATIONSHIPS BETWEEN AGE, SKIN COLOUR AND SKIN ELASTICITY
}

J S Everett*, J D Fargo, M S Sommers Correspondence: University of Pennsylvania, School of Nursing, 418 Curie Blvd, 241 2L Philadelphia, PA 19104, USA

10.1136/ip.2010.029215.840

Aims Our work demonstrates that after both rape and consensual sexual intercourse, women with light skin have higher ano-genital injury prevalence than women with dark skin. These findings suggest that the mechanical properties of dark skin may be more protective than those of light skin. If these findings are generalisable, they may have an impact on criminal justice proceedings, where injury from rapes is linked with successful legal outcomes. The purpose of this study was to determine whether there are differences in skin elasticity between females with dark skin, as compared to those with light skin.

Methods We enrolled 52 healthy female participants $\geq 18$ years $(M=30.8 ; S D=12.3)$, with a variety of ethnic backgrounds in a cross-sectional descriptive study, we measured skin colour ( $L^{*}=$ light/dark; $a^{*}=$ red/green; $b^{*}=$ yellow/blue) by means of spectrophotometry. We measured skin elasticity variables (eg, skin deformation, elasticity and recovery) with a Cutometer MPA580.

Results Skin colour L* values ranged from 796.96-7 229.33 $(M=6238.96 ; \mathrm{SD}=1116)$. While the correlation between skin colour and skin elasticity was insignificant $(\mathrm{r}=0.14)$, a statistically significant inverse relationship was found between age and skin elasticity $\left(\mathrm{r}^{2}=-0.62, \mathrm{p}<.0001\right)$.

Conclusions The strong inverse relationship of age and skin elasticity indicates an increased risk of skin injury as women age. This data did not support the theory that skin elasticity is associated with colour. Study limitations include a disproportionate number of participants $\leq 25$ years, with light skin, and self-identifying as White/Caucasian. Future work will include a larger sample, with greater parity across ages, race/ethnicities, and skin colours. 